Check for updates

Cite this: RSC Adv., 2017, 7, 33068

Received 27th April 2017

Accepted 13th June 2017

DOI: $10.1039 / c 7 r a 04731 b$

rsc.li/rsc-advances

\title{
Synthesis of novel sulfonated poly(arylene ether)s containing a tetra-trifluoromethyl side chain and multi-phenyl for proton exchange membrane fuel cell application $\dagger$
}

\author{
Yi-Chiang Huang, (D) Hsu-Feng Lee, Yu-Chao Tseng, Chun-Che Lee, Mei-Ying Chang \\ and Wen-Yao Huang*
}

Herein, a series of novel sulfonated poly(arylene ether)s consisting of tetra-trifluoromethyl-substituted multi-phenyl was synthesized via polycondensation, and post-sulfonation was carried out through chlorosulfonic acid to obtain sulfonated polymers possessing ion exchange capacities ranging from 1.27 to $2.53 \mathrm{mmol} \mathrm{g}{ }^{-1} \cdot{ }^{1} \mathrm{H} \mathrm{NMR}$ and FTIR spectroscopy were applied to confirm the structure and composition of the sulfonated polymers. The membranes exhibited considerable dimensional stability (with 3.1-27.8\% change in length; $17-56.5 \%$ change in thickness at $80{ }^{\circ} \mathrm{C}$ ) and excellent oxidative stability (weight remained higher than 97\%). The mechanical properties of the membranes demonstrated good tensile strength on account of the highly rigid multi-phenylated backbone, and Young's modulus ranged from 0.65 to $0.88 \mathrm{GPa}$. The proton conductivities of the membranes ranged from 0.03 to $0.24 \mathrm{~S}$ $\mathrm{cm}^{-1}$ at $80{ }^{\circ} \mathrm{C}$ under $95 \% \mathrm{RH}$, which were comparable to or higher than those of Nafion 211 . The morphology of the membranes demonstrated a clear hydrophilic/hydrophobic phase separation with spherical ionic clusters in the size range of 5-20 nm. SFC2-2.53 demonstrated a high current density (around $1800 \mathrm{~mA} \mathrm{~cm}{ }^{-2}$ at $0.6 \mathrm{~V}$ ) and the maximum power density of $1.41 \mathrm{~W} \mathrm{~cm}^{-2}$ for the fuel cell performance. The results indicated that SFC2 would be a good candidate for proton exchange membranes in fuel cell applications.

\section{Introduction}

A fuel cell (FC) converts chemical energy directly from a fuel into electricity, and has been presented as a promising alternative power source due to its high fuel conversion efficiency and low amount of pollutants. ${ }^{1,2}$ Proton exchange membrane fuel cells (PEMFCs) have received significant attention because of their low operation temperature/pressure ranges. Several important features of the PEMFCs depend upon the properties of the proton exchange membranes (PEMs). Therefore, PEMs are required to possess some of the following properties: high proton conductivity, low fuel and oxidant permeability, adequate electrochemical and chemical stability under FC operation conditions, dimensional and morphological stability, good mechanical properties, a satisfactorily low cost, and sufficient long term durability.,

Currently, Nafion membranes, which are perfluorinated sulfonic acid (PFSA) ionomer membranes, from DuPont are

Department of Photonics, National Sun Yat-Sen University, No. 70, Lienhai Rd., Kaohsiung 80424, Taiwan. E-mail: wyhuang@faculty.nsysu.edu.tw

$\dagger$ Electronic supplementary information (ESI) available. See DOI: $10.1039 / \mathrm{c} 7 \mathrm{ra} 04731 \mathrm{~b}$ deemed to be the most suitable PEMs and dominate the most demonstrated and commercialized PEMFC market owing to their good chemical and electrochemical stability as well as excellent proton conductivity. However, there are some disadvantages associated with Nafion: poor thermomechanical and chemical stability and decrease in the proton conductivity above $90{ }^{\circ} \mathrm{C}$ and under low humidity conditions. Moreover, the worst disadvantage is high material costs due to expensive fluorination and complex manufacturing processes..$^{5-8}$ In recent years, sulfonated hydrocarbon polymers have attracted significant attention as alternative polymer electrolyte membranes to Nafion. These sulfonated polymers, such as sulfonated poly (arylene ethers), sulfonated poly(arylene ether ketone)s, sulfonated polyimides, and sulfonated polybenzimidazoles, ${ }^{9,10}$ have been extensively investigated owing to the easy adjustment of their molecule structure, high thermal stability, good chemical stabilities, appropriate mechanical properties, processability, and low production cost. ${ }^{11-13}$

In general, sulfonated aromatic hydrocarbon polymers under high ion exchange capacity (IEC) can provide good proton conductivity and water uptake. However, high IEC value of PEMs is frequently accompanied by excessive swelling and deteriorated mechanical properties. ${ }^{14}$ Recently, we have 
reported a series of poly(arylene ether)s containing a high free volume multi-phenylated structure in the polymer backbone, which provides water sorption ability while maintaining mechanical and dimensional stability and demonstrates high proton conductivity. ${ }^{\mathbf{1 5 - 1 7}}$ Skalski et al. synthesized a sulfonated polyphenylene homopolymer with a high IEC value of $3.70 \mathrm{mmol} \mathrm{g}^{-1}$. The membranes were water-insoluble and exhibited higher proton conductivity as compared to Nafion 211 in the range of $50-95 \% \mathrm{RH} .{ }^{18} \mathrm{Lim}$ et al. reported a sulfonated poly(arylene ether ketone sulfone) block copolymer that consisted of non-planar conformation and a non-conjugated multiphenyl monomer. The membranes showed high water uptake and comparable proton conductivity as compared to Nafion 211. This result may be attributed to well-defined phase separation. ${ }^{19}$ As observed from many reported researches, partially fluorinated sulfonated polymers have demonstrated some advantages over non-fluorinated sulfonated polymers. The presence of fluorine substitution is expected to lead to good chemical stability and better hydrophilic/hydrophobic phase separation..$^{\mathbf{8 2 0 , 2 1}}$ Furthermore, the fluorine substituted group is a strongly electron-withdrawing group, which can deactivate the aromatic ring to prevent the attack of the sulfonating agent. ${ }^{22,23}$

Herein, we report the synthesis of novel poly(arylene ether)s composed of trifluoromethyl side chains on multi-phenylated bisfluoro monomer with fluorene-based and multi-phenylated bisphenol monomers. The trifluoromethyl group enables the deactivation of the aromatic ring to restrict the position of sulfonation and to increase phase separation and chemical stability. The high free volume of the multi-phenylated structure provides water sorption ability and preserves mechanical stability. The sulfonated poly(arylene ether)s were prepared via treatment with chlorosulfonic acid and confirmed by ${ }^{1} \mathrm{H}$ NMR and FTIR spectroscopies. The membranes were prepared via solution casting from dimethyl sulfoxide, and their PEM properties such as water uptake, dimensional stability, mechanical strength, proton conductivity, morphology, and single cell performance were characterized.

\section{Experimental}

\section{General methods}

All reagents and solvents were purchased from Alfa Aesar, Aldrich Chemical Co., Merck, Lancaster, Fisher Scientific or Tokyo Chemical Industry Co. and used without further purification. Toluene was dried over $\mathrm{CaH}$ and freshly distilled under a $\mathrm{N}_{2}$ atmosphere and deoxygenated by purging with $\mathrm{N}_{2}$ for $20 \mathrm{~min}$ prior to use. All reactions were performed under a prepurified $\mathrm{N}_{2}$ atmosphere. The synthesis of $4,4^{\prime}-\left(9,9^{\prime}\right.$-spirobi [fluorene]-2,7-diyl)diphenol and $2^{\prime \prime}, 3^{\prime \prime}, 5^{\prime \prime}, 6^{\prime \prime}$-tetraphenyl$\left[1,1^{\prime}: 4^{\prime}, 1^{\prime \prime}: 4^{\prime \prime}, 1^{\prime \prime \prime}: 4^{\prime \prime \prime}, 1^{\prime \prime \prime \prime}\right.$-quinquephenyl $]-4,4^{\prime \prime \prime \prime}$-diol was carried out by following the previously reported procedures. ${ }^{16,24,25}$

2,5-Bis(4-bromophenyl)-3,4-bis(3-(trifluoromethyl)phenyl) cyclopenta-2,4-dienone. 1,3-Bis(4-bromophenyl)propan-2-one (12.94 g, $1.44 \mathrm{mmol})$, 1,2-bis(3-(trifluoromethyl)phenyl)ethane1,2-dione (14.61 g, $1.44 \mathrm{mmol})$, and ethanol (100 mL) were placed in a 2-necked round-bottomed flask. The mixture was stirred at $125{ }^{\circ} \mathrm{C}$ and potassium hydroxide in ethanol (0.5 eq.) was added dropwise. The reaction mixture was stirred at $125^{\circ} \mathrm{C}$ for $0.5 \mathrm{~h}$ and allowed to cool down to room temperature. Methanol (50 $\mathrm{mL})$ was added, and the resulting precipitate was obtained and washed several times with methanol. A black purple solid was obtained in $87 \%$ yield after drying the precipitate under vacuum. ${ }^{1} \mathrm{H} \mathrm{NMR}\left(500 \mathrm{MHz}, \mathrm{CDCl}_{3}, \delta=\mathrm{ppm}\right)$ : 6.99-7.08 (s, 2H) 7.08-7.10 (m, 4H), 7.17-7.19 (d, 2H), 7.37-7.42 $(\mathrm{m}, 6 \mathrm{H}), 7.55-7.57$ (d, 2H). MALDI-TOF MS $\mathrm{m} / \mathrm{z}$ calcd: 677.95, found 677.42 .

$3^{\prime}, 6^{\prime}$-Bis(4-bromophenyl)-3, $3^{\prime \prime}$-bis(trifluoromethyl)-1, $1^{\prime}: 2^{\prime}, 1^{\prime \prime}$ terphenyl. A solution of 2,5-bis(4-bromophenyl)-3,4-bis(3trifluoromethylphenyl)cyclopenta-2,4-dienone $(21.84 \mathrm{~g}, \quad 32$ $\mathrm{mmol})$ and bicyclo[2.2.1]hepta-2,5-diene (3.56 g, $38 \mathrm{mmol})$ in toluene $(20 \mathrm{~mL})$ was introduced into a 2-necked round-bottomed flask with a stirring bar and a $\mathrm{N}_{2}$ inlet. The reaction mixture was heated to reflux for $24 \mathrm{~h}$. After being cooled down to room temperature, the resultant mixture was poured in methanol (150 $\mathrm{mL}$ ). The precipitate was obtained by filtration and washed several times with methanol. The crude product was purified via recrystallization from ethyl acetate/hexane, producing a white crystal in $79 \%$ yield. ${ }^{1} \mathrm{H}$ NMR $\left(500 \mathrm{MHz}, \mathrm{CDCl}_{3}, \delta=\mathrm{ppm}\right): 6.88-$ 7.14 (m, 10H), 7.24-7.25 (d, 2H), 7.32-7.33 (d, 4H), 7.52 (s, 2H). MALDI-TOF MS $m / z$ calcd: 675.97 , found 684.91 .

4,4'"'-Difluoro-3, $3^{\prime \prime \prime \prime \prime}$-bis(trifluoromethyl)-2", $3^{\prime \prime}$,-bis(trifluoro methyl)phenyl-[1, $1^{\prime}: 4^{\prime}, 1^{\prime \prime}: 4^{\prime \prime}, 1^{\prime \prime \prime}: 4^{\prime \prime \prime}, 1^{\prime \prime \prime \prime}$-quinquephenyl]. $\quad 3^{\prime}, 6^{\prime}-$ Bis(4-bromophenyl)-3, $3^{\prime \prime}$-bis(trifluoromethyl)-1, $1^{\prime}: 2^{\prime}, 1^{\prime \prime}$-terphenyl (5 g, $7.3 \mathrm{mmol}$ ), 4-fluoro-3-trifluoromethyl phenyl boronic acid (3.7 g, $17 \mathrm{mmol}), \mathrm{Pd}\left(\mathrm{PPh}_{3}\right)_{4}(0.084 \mathrm{~g}, 0.073 \mathrm{mmol}), 2 \mathrm{M}$ potassium carbonate solution, and toluene $(150 \mathrm{~mL})$ were placed in a flamedried flask equipped with a stirring bar and refluxed for $24 \mathrm{~h}$ under a $\mathrm{N}_{2}$ atmosphere. After being cooled down, the mixture was poured in water and extracted twice with toluene and brine. The combined organic layer was dried over $\mathrm{MgSO}_{4}$, and the solvent was removed under reduced pressure to obtain a light yellow solid. The crude monomer was purified via recrystallization from dichloromethane/hexane to obtain pure white M1 in 84\% yield. ${ }^{1} \mathrm{H}$ NMR (500 $\left.\mathrm{MHz}, \mathrm{CDCl}_{3}, \delta=\mathrm{ppm}\right): 6.79-7.70(\mathrm{~m}$, $34 \mathrm{H}, \mathrm{ArH})$. MALDI-TOF MS $m / z$ calcd: 842.17 , found 841.20.

\section{General procedure for the synthesis of FC polymers}

Polymerization reactions were carried out in a three-necked 100 mL flame-dried flask equipped with a stirring bar and a DeanStark apparatus fitted with a condenser under a $\mathrm{N}_{2}$ atmosphere. The flask was charged with M1 $(2.33 \mathrm{mmol})$, bisphenol monomer (2.33 mmol), potassium carbonate $(0.8 \mathrm{~g}, 5.78 \mathrm{mmol})$, dimethylacetamide (DMAC) $(20 \mathrm{~mL})$, and toluene $(15 \mathrm{~mL})$. The reaction mixture was stirred at $130{ }^{\circ} \mathrm{C}$ for $2 \mathrm{~h}$ to remove toluene and water; then, the reaction temperature was increased to $160{ }^{\circ} \mathrm{C}$ for $24 \mathrm{~h}$. After being cooled down to room temperature, the crude mixture was poured in methanol and deionized water to precipitate a light yellow-white fibrous polymer. The polymer was filtered, washed several times with water and hot methanol, and dried in vacuum at $80^{\circ} \mathrm{C}$ for $8 \mathrm{~h}$.

\section{General procedure for sulfonation}

To a solution of the polymer $(1.2 \mathrm{~g})$ in dichloromethane $(75 \mathrm{~mL})$ at room temperature, chlorosulfonic acid in dichloromethane 
was added drop-wise. The reaction mixture was stirred for $24 \mathrm{~h}$ and then poured in water. The polymer precipitate was filtered, washed thoroughly with deionized water until $\mathrm{pH}$ became neutral, and then dried in vacuum at $60{ }^{\circ} \mathrm{C}$ overnight to obtain the sulfonated polymer. To prepare variety degrees of sulfonation, polymers were sulfonated to different extents according to the above procedure by adding $6 \mathrm{~mL}$ and $14 \mathrm{~mL}$ of chlorosulfonic acid, respectively. The sulfonated polymer was readily soluble in polar aprotic solvents such as DMF, DMAC, DMSO, and NMP.

The ion exchange capacity (IEC) of the membranes was determined by acid-base titration. The dried membrane was weighted and immersed in $1.0 \mathrm{M} \mathrm{HCl}$ solution for $24 \mathrm{~h}$ to protonate the acid groups and washed thoroughly with deionized water to reach a neutral $\mathrm{pH}$. Then, the membrane was immersed in a $1.0 \mathrm{M}$ solution of $\mathrm{NaCl}$ for $24 \mathrm{~h}$, such that to replace the protons of sulfonic acid groups by $\mathrm{Na}$ ions. The solutions were titrated using a $0.01 \mathrm{M} \mathrm{NaOH}$ solution, and phenolphthalein was used as an indicator. The IEC $\left(\mathrm{mmol} \mathrm{g}^{-1}\right)$ values were calculated from the titration results using the following equation: IEC $\left(\mathrm{mmol} \mathrm{g}^{-1}\right)=\left(V_{\mathrm{NaOH}} \times M_{\mathrm{NaOH}}\right) / W_{\mathrm{dry}}$, where $V_{\mathrm{NaOH}}$ and $M_{\mathrm{NaOH}}$ are the volume and concentration of the $\mathrm{NaOH}$ solution, respectively, and $W_{\text {dry }}$ is the weight of the dry membrane.

\section{Measurements}

${ }^{1} \mathrm{H}$ NMR and ${ }^{19} \mathrm{~F}$ NMR spectroscopic measurements were carried out via a $500 \mathrm{MHz}$ Varian UNITY INOVA-500 spectrometer using $\mathrm{CDCl}_{3}$ or DMSO- $\mathrm{d}_{6}$ as the solvent. MALDI-TOF mass spectrum was obtained via a Bruker Daltonics, autoflex III TOF/ TOF using 2,5-dihydroxybenzoic acid as the matrix. FTIR spectrum of the polymer membranes was obtained using a Bruker VERTEX 70 FTIR spectrometer. The gel permeation chromatographic (GPC) analysis was carried out using Viscotek 270 max with a refractive index detector (Viscotek model 270, THF used as the eluent, flow rate of $1 \mathrm{~mL} \mathrm{~min}^{-1}$ ). For calibration, polystyrene standard (molecular weight between 6770 and 281000 Da) was used. Thermal stability of the polymers was evaluated via thermogravimetric analysis (TGA) that was carried out using a Perkin Elmer Pyris 1 instrument from $50{ }^{\circ} \mathrm{C}$ to $800{ }^{\circ} \mathrm{C}$ at a heating rate of $10{ }^{\circ} \mathrm{C}$ min under a $\mathrm{N}_{2}$ atmosphere. Before the analysis, the membranes were dried in the TGA furnace at $130{ }^{\circ} \mathrm{C}$ under $\mathrm{N}_{2}$ for $20 \mathrm{~min}$ to remove water. Thermal mechanical analyses (TMA) were performed on film specimens (length, $10 \mathrm{~mm}$; width, $2 \mathrm{~mm}$; and thickness, 30-40 $\mu \mathrm{m}$ ) using the Seiko Pyris Diamond TMA at $25{ }^{\circ} \mathrm{C}$.

\section{Water uptake and dimensional stability}

Water uptake was the measured weight from the mass increase of the membranes immersed in deionized water for $24 \mathrm{~h}$ as the temperature increased from 30 to $80{ }^{\circ} \mathrm{C}$. The water uptake was calculated using the following equations.

$$
\text { Water uptake }(\%)=\left(W_{\text {wet }}-W_{\text {dry }}\right) / W_{\text {dry }} \times 100 \%
$$

where $W_{\text {wet }}$ and $W_{\text {dry }}$ are the weights of the wet and dry membranes, respectively.

The swelling ratio was measured from the change in the dimension of membranes immersed in deionized water for $24 \mathrm{~h}$ as the temperature was increased from 30 to $80{ }^{\circ} \mathrm{C}$ and calculated using the following equations:

$$
\text { In plane swelling ratio (\%): } \Delta L=\left(L_{\mathrm{wet}}-L_{\mathrm{dry}}\right) / L_{\mathrm{dry}} \times 100 \%
$$

Through plane swelling ratio ( $\%): \Delta T=\left(T_{\text {wet }}-T_{\text {dry }}\right) / T_{\text {dry }} \times 100 \%$

where $L_{\text {wet }}$ and $L_{\text {dry }}$ are the lengths of the wet and dry membranes and $T_{\text {wet }}$ and $T_{\text {dry }}$ are the thickness of the wet and dry membranes, respectively.

\section{Stability}

The membranes were weighed and soaked in Fenton's reagent ( $3 \% \mathrm{H}_{2} \mathrm{O}_{2}$ aqueous solution containing $2 \mathrm{ppm}^{\mathrm{FeSO}} \mathrm{S}_{4}$ ) at $80{ }^{\circ} \mathrm{C}$ for $1 \mathrm{~h}$. The oxidative stability was evaluated by change in the weight of the membranes after being attacked by the Fenton's reagent. Hydrolytic stability of the membranes was evaluated by immersing the membranes in water at $140{ }^{\circ} \mathrm{C}$ for $24 \mathrm{~h}$.

\section{Proton conductivity}

The proton conductivity measurements of the membranes were conducted using an AC impedance analyzer (Agilent 4294A Precision Impedance Analyzer) along the in-plane direction over a frequency range of $10 \mathrm{M}$ to $100 \mathrm{~Hz}$ at a voltage amplitude of $100 \mathrm{mV}$. The conductivity was measured after clamping a $10 \times$ $20 \mathrm{~mm}$ sample piece between two platinum electrodes of a conductivity cell. The test cell was placed in a FIRSTEK BTH80/-20 environmental chamber to measure conductivity at $80{ }^{\circ} \mathrm{C}$ with varied relative humidity. Proton conductivity $(\sigma)$ was then calculated by the equation $\sigma=L / R A$, where $L(\mathrm{~cm})$ is the distance between electrodes, $R(\Omega)$ is the membrane resistance, and $A\left(\mathrm{~cm}^{2}\right)$ is the cross-sectional area of the sample.

\section{Microstructure analysis}

Transmission electron microscopy (TEM) was performed using a JEOL, JEM-2100 (HR) TEM, operated at an accelerating voltage of $200 \mathrm{kV}$. For this study, the acid form of the membranes was stained and converted into $\mathrm{Ag}^{+}$ion via overnight immersion in $1 \mathrm{M} \mathrm{AgNO}_{3}$. Subsequently, the membranes were washed thoroughly with deionized water and dried at room temperature for $24 \mathrm{~h}$. The stained membranes were placed in an enclosure of epoxy resin and ultra-microtomed under cryogenic conditions with a thickness of $70 \mathrm{~nm}$.

\section{Single cell performance}

Catalyst inks were prepared by mixing Pt/C (HiSPEC 4000, Alfa Aesar) and 5 wt\% Nafion D520 binder. The ink was loaded on both sides of the membrane via a spraying method. The active surface area was $5 \mathrm{~cm}^{2}$ with an overall Pt loading of $0.4 \mathrm{mg}$ $\mathrm{cm}^{-2}$. The membrane electrolyte assemble (MEA) was obtained via the construction of the SFC membrane sandwiched between two gas diffusion layers (GDL 24BC, Hephas Energy Co., Ltd.). 
The MEA of the Nafion 211 membrane was fabricated via the same procedure as a reference. The anode and cathode were supplied with hydrogen at a flow rate of $0.3 \mathrm{~L} \mathrm{~min}^{-1}$ and oxygen at a flow rate of $0.5 \mathrm{~L} \mathrm{~min}^{-1}$, respectively. The fabricated cell was activated for $5 \mathrm{~h}$ with hydrogen and oxygen at $80{ }^{\circ} \mathrm{C}$ and $100 \%$ relative humidity.

\section{Results and discussion}

\section{Synthesis and characterization of the monomers and polymers}

A novel tetra-trifluoromethyl side chain-substituted monomer was successfully synthesized via three synthetic steps, as shown in Scheme 1. The monomer 1 was synthesized from 1,3-bis(4bromophenyl)propan-2-one and 3,3"-bis(trifluoromethyl)benzil via aldol condensation. Then, the monomer 1 was reacted with 2,5-norbornadiene via Diels-Alder reaction to obtain monomer 2. Finally, 4,4"'!'-difluoro-3, $3^{\prime \prime \prime \prime}$-bis(trifluoromethyl)- $2^{\prime \prime}, 3^{\prime \prime}$, -bis(trifluoromethyl) phenyl-[1, $1^{\prime}: 4^{\prime}, 1^{\prime \prime}: 4^{\prime \prime}, 1^{\prime \prime \prime}: 4^{\prime \prime \prime}, 1^{\prime \prime \prime \prime}$-quinquephenyl] (monomer 3) was prepared from monomer 2 and 4fluoro-3-trifluoromethyl phenyl boronic acid through Suzuki coupling. The monomers were confirmed via ${ }^{1} \mathrm{H}$ NMR and MALDI-TOF MS spectroscopy, as shown in the ESI. $\dagger$

The polymers were prepared via a one-pot nucleophilic polycondensation with monomer 3 and diol monomers, 4,4'(9,9'-spirobi[fluorene]-2,7-diyl)diphenol and $2^{\prime \prime}, 3^{\prime \prime}, 5^{\prime \prime}, 6^{\prime \prime}$-tetraphenyl-[1, $1^{\prime}: 4^{\prime}, 1^{\prime \prime}: 4^{\prime \prime}, 1^{\prime \prime \prime}: 4^{\prime \prime \prime}, 1^{\prime \prime \prime \prime}$-quinquephenyl $]-4,4^{\prime \prime \prime \prime}$-diol, which were denoted as FC1 and FC2, respectively, as shown in Scheme 2. The obtained polymers were readily soluble in common solvents such as DMAc, NMP, THF, and chloroform. The molecular weight of the polymers was determined by gel permeation chromatography (GPC). The FC1 and FC2 showed high molecular weight of 245 and $150 \mathrm{kDa}$ and polydispersity index (PDI) of 4.0 and 3.7, respectively. These results indicated that the 2-perfluoroalkyl substitution in the phenyl groups activating the ortho-fluoro displacement was sufficient to

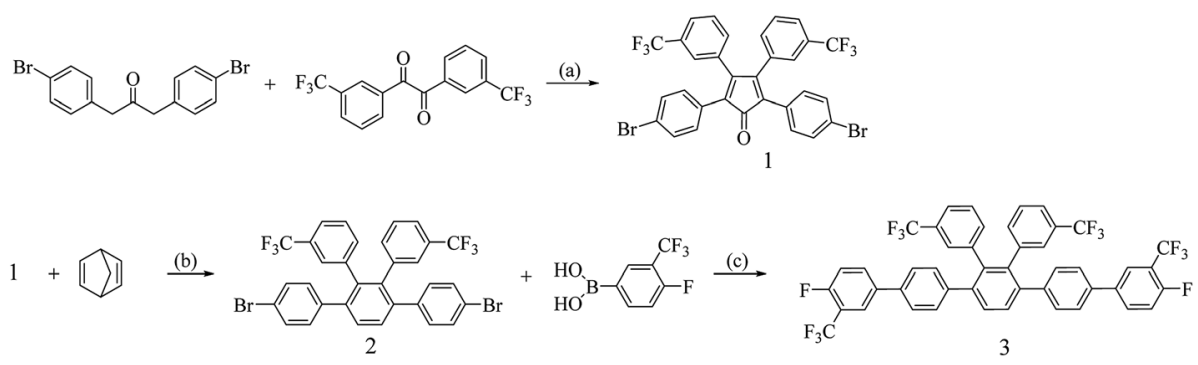

Scheme 1 Synthesis of monomer (a) Triton B, triethylene glycol, $120{ }^{\circ} \mathrm{C}$ (b) toluene, reflux (c) $\mathrm{Pd}\left(\mathrm{PPh}_{3}\right)_{4}, \mathrm{THF}$, toluene, $\mathrm{K}_{2} \mathrm{CO} \mathrm{O}_{3}$, reflux.

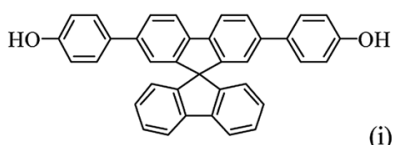

(i)

monomer $3+$

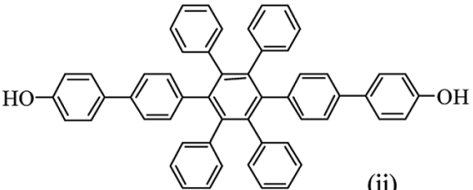

(ii)

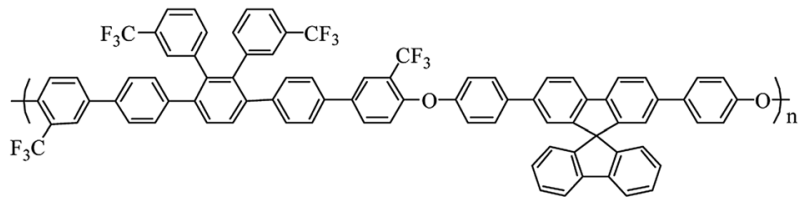

$\stackrel{\text { (a) }}{\longrightarrow}$

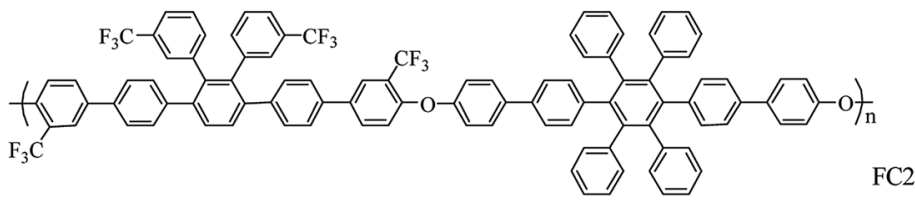

$\mathrm{FC} 1$

$\mathrm{SFC1}$

(b)
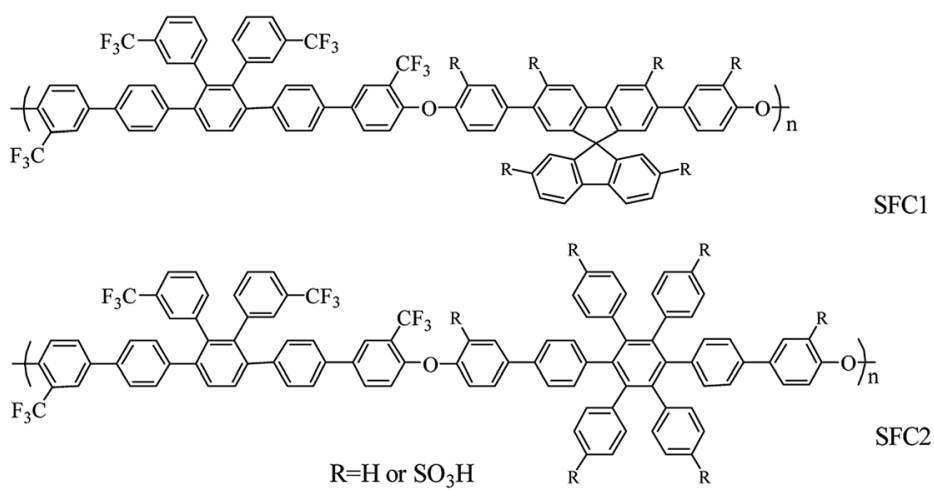

Scheme 2 Synthesis of sulfonated polymers (a) $\mathrm{K}_{2} \mathrm{CO}_{3}, \mathrm{DMAc}, 160{ }^{\circ} \mathrm{C}$; (b) $\mathrm{HSO}_{3} \mathrm{Cl}_{\mathrm{CH}} \mathrm{Cl}_{2}$. 
obtain high molar mass poly(arylene ether)s during polymerization. ${ }^{26,27}$

Post-sulfonation of the FC polymers was carried out using various degrees of chlorosulfonic acid to obtain SFC1-X and SFC2-X, where $\mathrm{X}$ represents the value of IEC, and the structures were confirmed by the ${ }^{1} \mathrm{H}$ NMR spectrum. NMR signals of SFC11.55 and SFC2-2.53 are shown in Fig. 1 and 2, respectively. Generally, substitution reaction by chlorosulfonic acid preferentially occurs on electron-rich aromatic rings. The new signal appears at $7.75 \mathrm{ppm}$ due to the presence of the sulfonic acid group (labeled 13). The new signal at $7.9 \mathrm{ppm}$ is assigned to the proton next to the sulfonated pendant benzene ring (labeled 17), showing a similar chemical shift as reported in our previous work. ${ }^{15,17}$ The ${ }^{19}$ F-NMR spectrum showed the signals of the trifluoromethyl group of unsulfonated polymers that were assigned to be at -66 and $-68 \mathrm{ppm}$. After sulfonation, the signals of trifluoromethyl were still observed and deshielded to -64 and -65 ppm, as shown in the ESI (Fig. S6 $\dagger$ ).

The post-sulfonation reaction was also substantiated from the FTIR spectra, as shown in Fig. 3. The absorption peaks at around 1463 and $1492 \mathrm{~cm}^{-1}$ are assigned to the phenyl ring, and the peak at $1603 \mathrm{~cm}^{-1}$ is assigned to the $\mathrm{C}=\mathrm{C}$ stretching
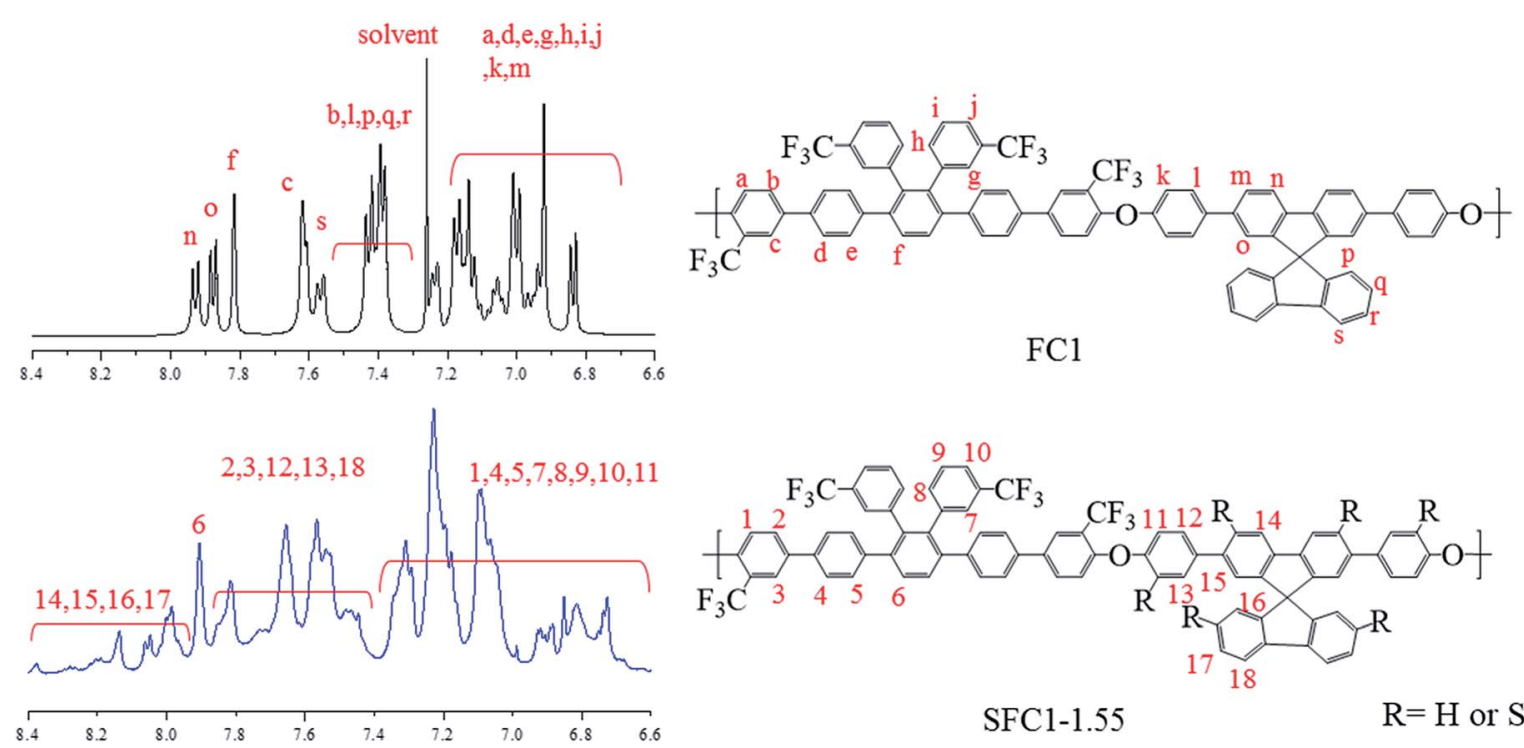

SFC1-1.55

$\mathrm{R}=\mathrm{H}$ or $\mathrm{SO}_{3} \mathrm{H}$

Fig. $1{ }^{1} \mathrm{H}$ NMR spectrum of polymer FC1 (top) and after sulfonation (SFC1-1.55) (bottom).
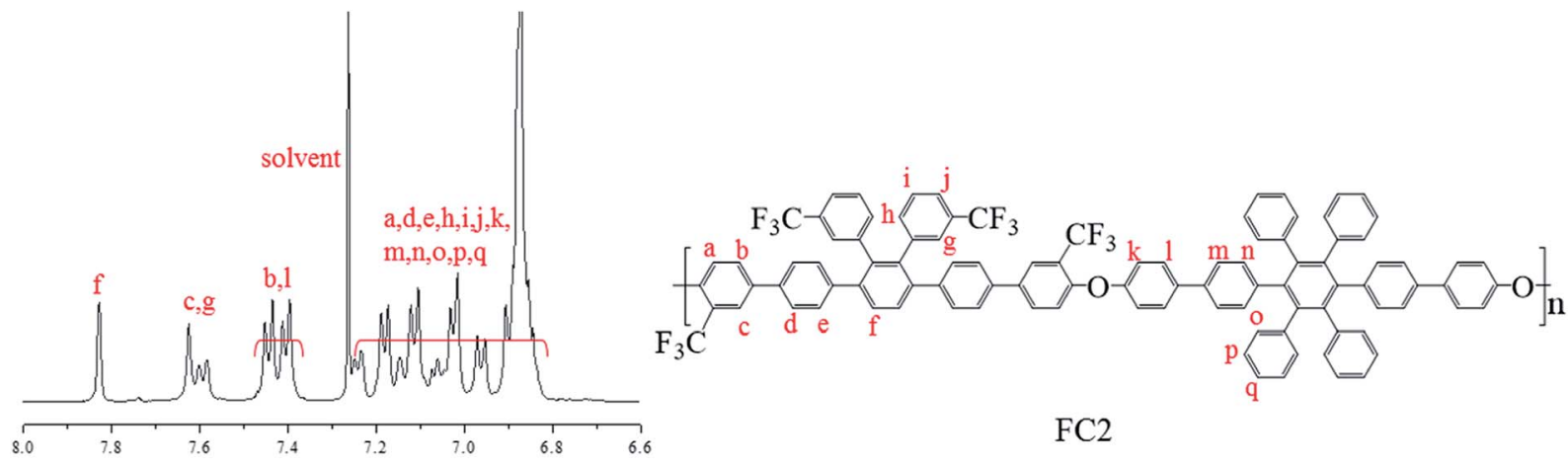

$\mathrm{FC} 2$
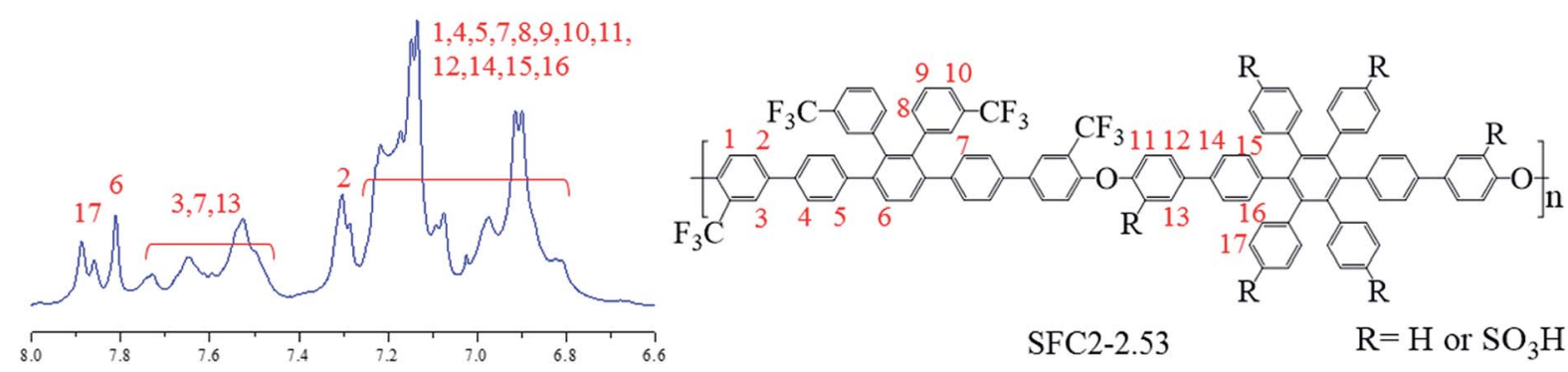

Fig. $2{ }^{1} \mathrm{H}$ NMR spectrum of the polymer FC2 (top) and after sulfonation (SFC2-2.53) (bottom). 


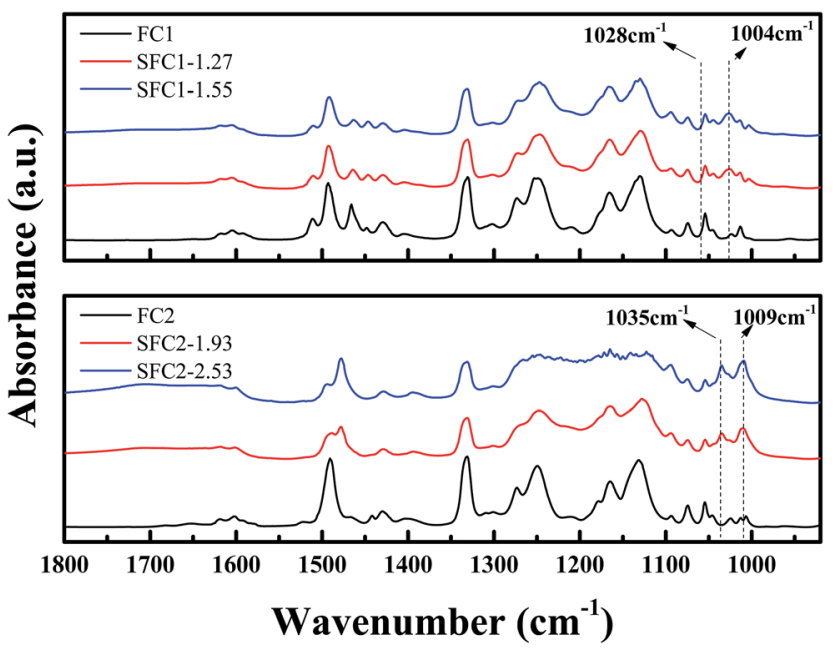

Fig. 3 FTIR spectra of the polymers, SFC1 (top) and SFC2 (bottom).

vibrations. Characteristic band at $1004 \mathrm{~cm}^{-1}$ was attributed to the in-plane bending vibration of a sulfonic acid group substituted at a phenyl ring, and the peaks at $1028-1035 \mathrm{~cm}^{-1}$ were assigned to the symmetric stretching of the $\mathrm{O}=\mathrm{S}=\mathrm{O}$ group. $^{16,28,29}$

\section{Thermal stability}

Thermogravimetric analysis curves are shown in Fig. 4, and the $5 \%$ weight loss temperatures $\left(T_{\mathrm{d}} 5 \%\right)$ for sulfonated polymers are extracted in Table 1 . The unsulfonated polymers FC1 and FC2 demonstrated excellent thermal stability with $5 \%$ weight loss temperatures of $598{ }^{\circ} \mathrm{C}$ and $605{ }^{\circ} \mathrm{C}$, respectively. All the sulfonated polymers exhibited a similar trend, which consisted of three degradation steps. An initial weight loss before $200{ }^{\circ} \mathrm{C}$ was related to the removal of hydrated water and solvent. The secondary degradation curve observed at around $200-400{ }^{\circ} \mathrm{C}$ was attributed to the decomposition of sulfonic acid groups. The last step occurring above $450{ }^{\circ} \mathrm{C}$ consists of the degradation of the remaining polymer main chain.

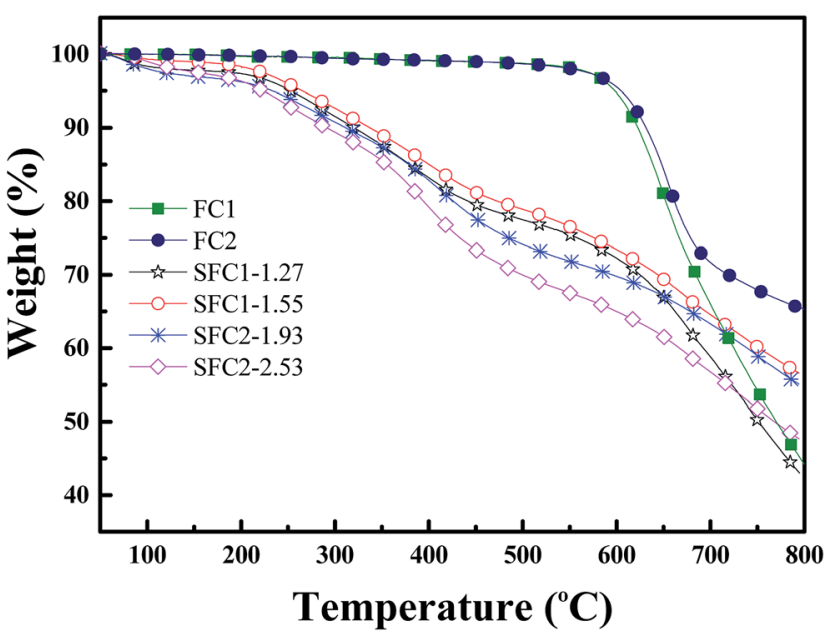

Fig. 4 Thermogravimetric analysis curves of the sulfonated polymers.
Table 1 Thermal stability and mechanical properties of the SFC membranes

\begin{tabular}{lllll}
\hline & $\begin{array}{l}T_{\mathrm{d}} 5 \% \\
\left({ }^{\circ} \mathrm{C}\right)\end{array}$ & $\begin{array}{l}\text { Young's } \\
\text { modulus (GPa) }\end{array}$ & $\begin{array}{l}\text { Tensile } \\
\text { strength }^{a}(\mathrm{MPa})\end{array}$ & $\begin{array}{l}\text { Elongation } \\
\text { at break }^{a}(\%)\end{array}$ \\
\hline $\mathrm{SFC} 1-1.27$ & 254 & 0.88 & 92.1 & 37.8 \\
$\mathrm{SFC1}-1.55$ & 243 & 0.81 & 66.0 & 29.6 \\
$\mathrm{SFC} 2-1.93$ & 240 & 0.77 & 72.4 & 35.9 \\
$\mathrm{SFC2}-2.53$ & 224 & 0.65 & 51.7 & 24.6 \\
Nafion 211 & - & 0.10 & 26.6 & 146.6 \\
${ }^{a}$ Measured at 25 ${ }^{\circ} \mathrm{C}$ and 40\% RH. & & \\
\end{tabular}

\section{Mechanical properties}

The mechanical properties of the SFC series (acid form) membranes were measured as shown in Fig. 5 and are listed in Table 1. Tensile strength (51-92 MPa) and Young's modulus $(0.65-0.88 \mathrm{GPa})$ were much higher than those of the Nafion 211 membrane (26 MPa and 0.10 MPa, respectively). However, the SFC membranes exhibited much lower elongations at break (24 to $38 \%$ ) because of the presence of bulky and rigid multiphenylated backbone structures as compared to the soft liner perfluorocarbons structure of Nafion 211 membrane (146\%). This result was very similar with that of other sulfonated aromatic hydrocarbon polymers reported in previous literatures. ${ }^{30-32}$

\section{Water uptake, dimensional stability, and oxidative stability}

The water uptake of PEMs plays an important role in evaluating the proton conductivity because water molecules are proton transportation carriers in the PEMs. However, excessive water uptake may prompt improper dimensional changes and loss of the mechanical durability. The water uptake (Fig. 6) and dimensional stability of the SFC series membranes were investigated, and the results are listed in Table 2. As expected, the water uptake of the membranes increased with an increase

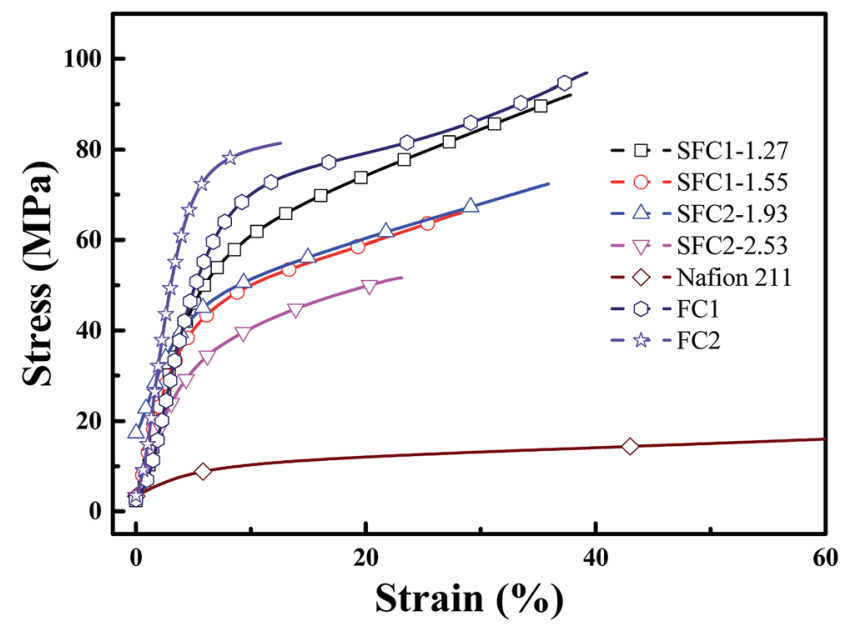

Fig. 5 Stress-strain curves of the sulfonated membranes at $25^{\circ} \mathrm{C}$ and $40 \% \mathrm{RH}$. 


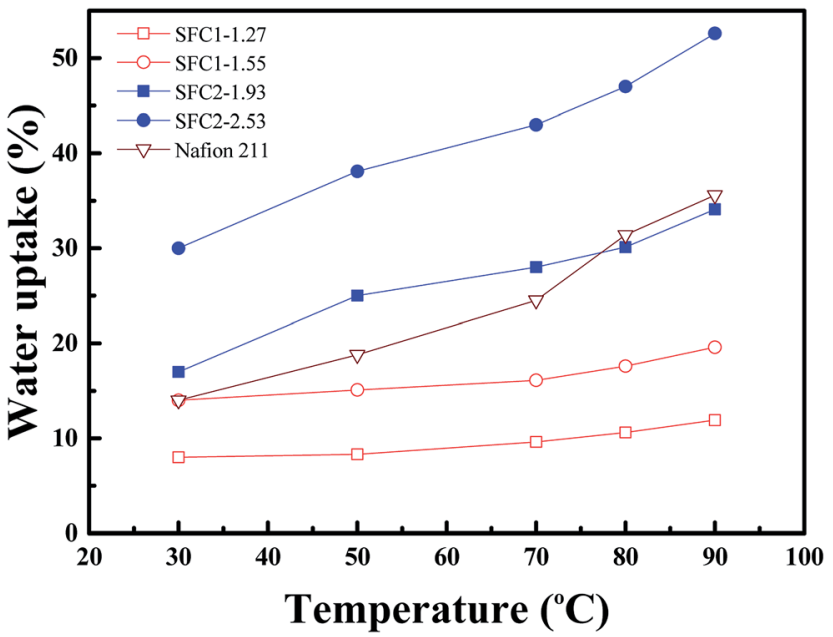

Fig. 6 Water uptake as a function of temperature for SFC membranes.

in temperature and IEC value. Water uptake of the SFC1 series membranes is in the range from 8 to $14 \%$ at $30{ }^{\circ} \mathrm{C}$, whereas it is in the range of $10.6-17.6 \%$ at $80{ }^{\circ} \mathrm{C}$. Compared to Nafion 211 , SFC2-1.93 exhibited an approximate water uptake in all temperature ranges (around $30 \%$ at $80{ }^{\circ} \mathrm{C}$ ). SFC2-2.53 demonstrated highest water uptake $(47.3 \%)$, which was larger than that of Nafion 211. Due to increased hydrophilicity, higher IEC membranes are able to absorb more water.

The swelling of the SFC1 series membranes caused less than $5.7 \%$ change in the length and $28.6 \%$ change in the thickness at $80{ }^{\circ} \mathrm{C}$ because of lower degree of sulfonation. SFC2-1.93 showed an excellent dimensional stability with $10 \%$ change in length and $24 \%$ change in thickness at $80{ }^{\circ} \mathrm{C}$. The SFC2-2.53 with the highest IEC exhibited the highest water uptake ability but was also accompanied by largest dimensional changes $(\Delta L=27.8 \%$ and $\Delta T=56.5 \%$ at $80{ }^{\circ} \mathrm{C}$ ). However, the SFC2 series showed a higher IEC value and retained an appropriate swelling ratio compared to the SFC1 series and Nafion 211. This result may be attributed to the high free volume and rigidity of the tetraphenylated structure, which allowed water occupancy and was able to maintain acceptable swelling ratio of the membranes. ${ }^{17,33,34}$

It is known that the oxidative radicals such as $\mathrm{HO}^{\circ}$ and $\mathrm{HOO}^{\circ}$ originate from excess oxygen during the fuel cell operation. In order to evaluate the oxidative stability, the membranes were soaked in Fenton's reagent, a highly oxidative reagent. ${ }^{35}$ Oxidative stability of the SFC membranes was examined by observing the weight loss after treatment with the Fenton's reagent. All the membranes exhibited excellent oxidative stability, as shown in Table 3. The weight loss of the membranes was less than $3 \%$ after treatment with the Fenton's reagent at $80{ }^{\circ} \mathrm{C}$ for $1 \mathrm{~h}$. After $22 \mathrm{~h}$, very small fragments of SFC1-1.55 and SFC2-2.53 were found. However, the membranes still remained insoluble in Fenton's reagent after $24 \mathrm{~h}$ of treatment at $80{ }^{\circ} \mathrm{C}$, which showed similar or higher stability than other reported polymers. ${ }^{11,32,36,37}$ Due to their fully aromatic structure, the polymers demonstrated high oxidative stability. Furthermore, previous literature indicated that the presence of trifluoromethyl substituents in the polymer is effective for the formation of an electron deficient structure, which can improve the oxidative stability of a PEM. ${ }^{31,38}$ The hydrolytic stability of the membranes was examined by immersing them in water at

Table 2 IEC, water sorption, and dimensional stability of the SFC membranes

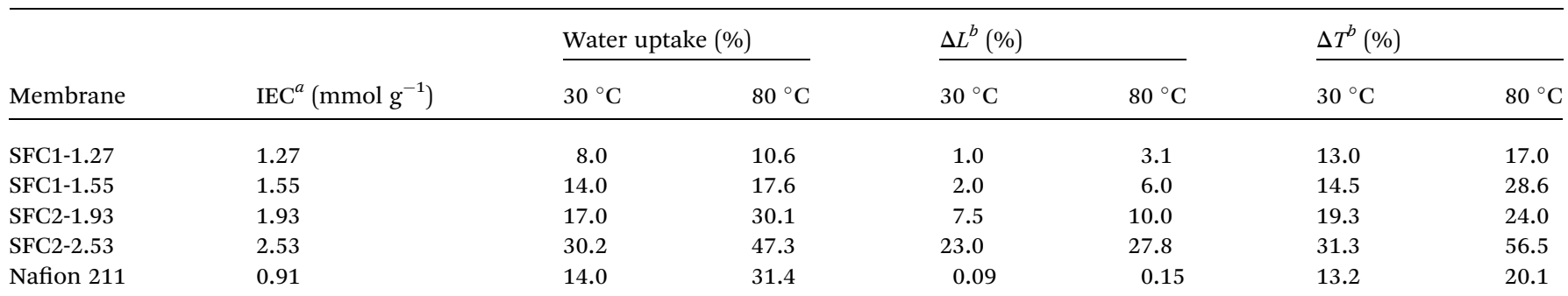

${ }^{a}$ IEC determined by acid-base titration. ${ }^{b}$ Change in film length $(\Delta L)$ and thickness $(\Delta T)$.

Table 3 Proton conductivity and stability of the SFC membranes

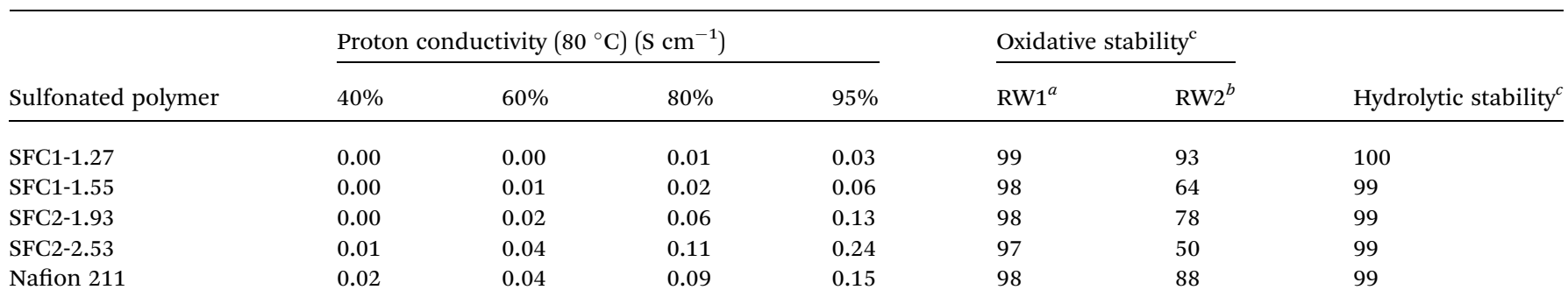

${ }^{a}$ Residual weight (\%) of membranes after heating in Fenton's reagent at $80^{\circ} \mathrm{C}$ for $1 \mathrm{~h} .{ }^{b}$ Residual weight (\%) of membranes after heating in Fenton's reagent at $80^{\circ} \mathrm{C}$ for $24 \mathrm{~h} .{ }^{c}$ After heating in water at $140{ }^{\circ} \mathrm{C}$ for $24 \mathrm{~h}$. 
$140{ }^{\circ} \mathrm{C}$ for $24 \mathrm{~h}$, and the results are listed in Table 3 . All the membranes exhibited excellent hydrolytic stability with weight loss lower than $1 \%$.

\section{Proton conductivity}

The proton conductivities of the SFC series membranes were measured at $80{ }^{\circ} \mathrm{C}$ with the increasing relative humidity, as shown in Fig. 7, and that of Nafion 211 was also measured under the same conditions, as a reference. All the SFC membranes exhibited a dependence of the proton conductivity on the relative humidity. The SFC1 series membranes showed lower conductivities than Nafion 211, with the highest conductivity being $0.06 \mathrm{mS} \mathrm{cm} \mathrm{cm}^{-1}$ (SFC1-1.55) at 95\% RH. For comparison, the highest conductivity for Nafion 211 was $0.15 \mathrm{~S}$

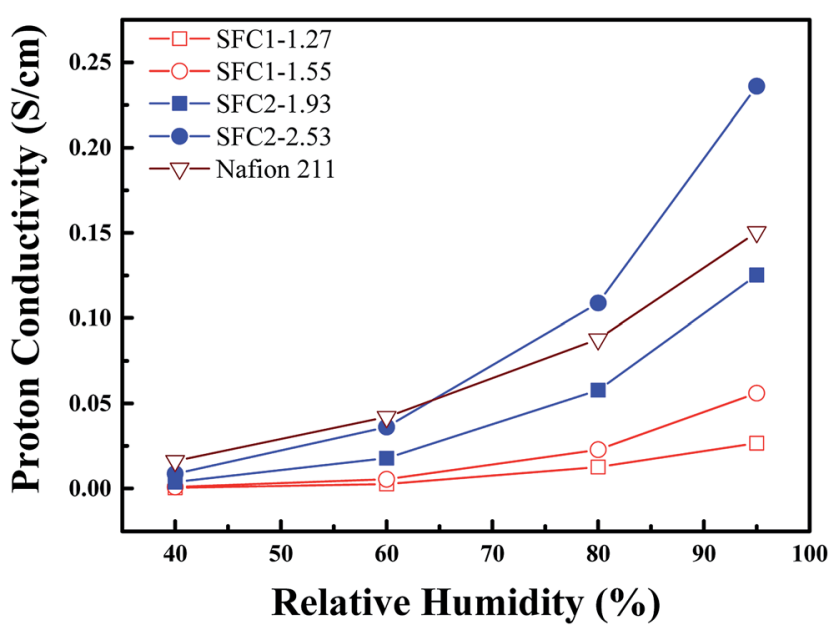

Fig. 7 Proton conductivity of the SFC membranes as a function of relative humidity. $\mathrm{cm}^{-1}$ at the same condition. The SFC2 series membranes showed a similar increasing trend as Nafion 211 under increasing RH. SFC2-1.93 exhibited the same conductivity from 0.02 to $0.13 \mathrm{~S} \mathrm{~cm}^{-1}$ (60\% to $\left.95 \% \mathrm{RH}\right)$. As compared to Nafion 211, SFC2-2.53 demonstrated a comparable conductivity from 40 to $60 \% \mathrm{RH}$ that was able to transcend when $\mathrm{RH}$ was greater than $65 \%$ and reached $0.24 \mathrm{~S} \mathrm{~cm}^{-1}$ under fully hydrated states (95\% RH). Table 3 displays the proton conductivities of the SFC series membranes.

\section{Microstructure analysis}

The microstructure of the SFC series membranes was investigated by TEM, as shown in Fig. 8. In the images, the dark areas represent the hydrophilic (sulfonate groups) domain and the brighter areas represent the hydrophobic (polymer backbones) domain. As presented in the images, excellent well-dispersed hydrophilic/hydrophobic phase separation was observed throughout the membrane in all the cases. The microstructures of SFC1-1.27 and SFC1-1.55 exhibited clearly spherical ionic clusters of around 2-8 $\mathrm{nm}$ and 5-10 $\mathrm{nm}$ diameter, respectively. The diameter of the ionic clusters of the SFC1 series membranes slightly increased with the increasing IEC value. SFC2 series membranes also displayed clearly spherical ionic clusters. SFC2-1.93 exhibited small amount of particle aggregation and loose ionic clusters ( $c a .2-15 \mathrm{~nm}$ ). The membrane with the highest IEC value, SFC2-2.53, was the most dense and had a uniform size ( $c a$. 2-4 nm) with slightly interconnected ionic clusters, very similar to Nafion $211 .^{39}$ The small and numerous sulfonic acid clusters could contribute to the formation of narrow and well-connected proton channels. ${ }^{\mathbf{4 0}}$ This may explain why SFC2-2.53 achieved highest proton conductivity and was accompanied with higher water uptake and dimensional changes.

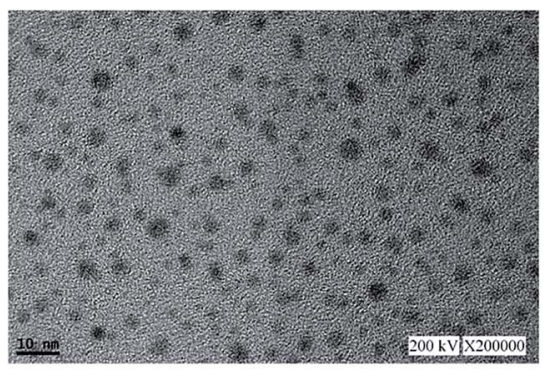

SFC1-1.27

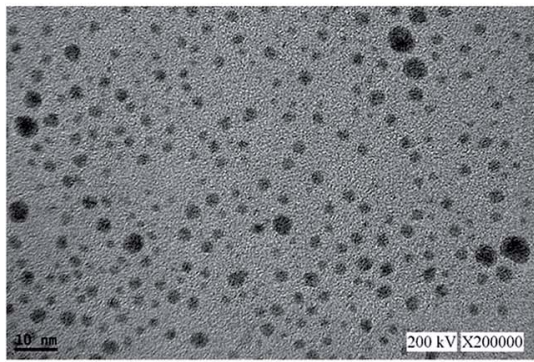

SFC2-1.93

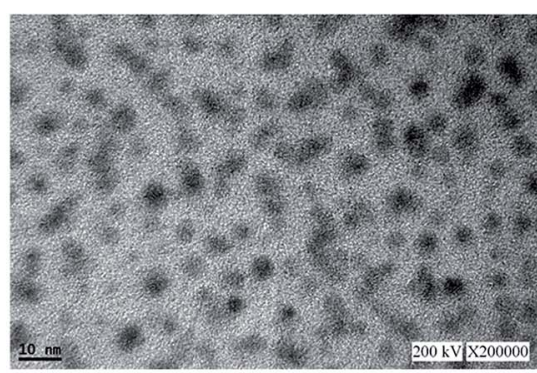

SFC1-1.55

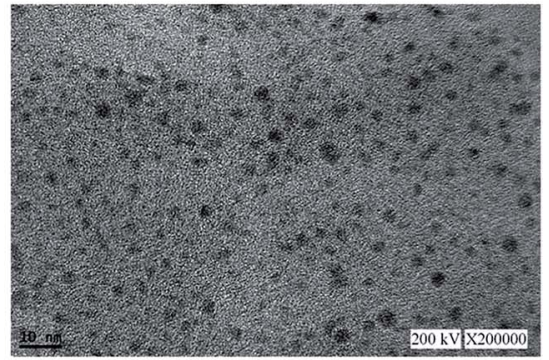

SFC2-2.53

Fig. 8 TEM image of SFC1-1.27, SFC1-1.55, SFC2-1.93, and SFC2-2.53 membranes. 


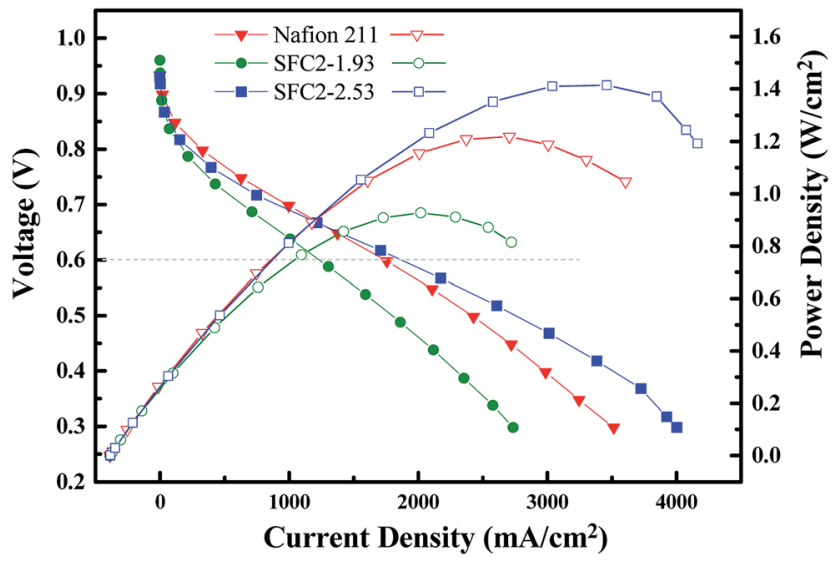

Fig. 9 Fuel cell performance of SFC2 and Nafion 211 membranes at $80{ }^{\circ} \mathrm{C}$ under $100 \% \mathrm{RH}$.

\section{Fuel cell performance}

Preliminary $\mathrm{H}_{2} / \mathrm{O}_{2}$ fuel cell performance of SFC2-1.93 $(30 \mu \mathrm{m})$, SFC2-2.53 $(17 \mu \mathrm{m})$, and Nafion $211(25 \mu \mathrm{m})$ was examined at $80{ }^{\circ} \mathrm{C}$ under fully hydrated conditions (100\% RH). As shown in Fig. 9, both the SFC2-1.93 and SFC2-2.53 membranes demonstrated good performance and had comparable power density to that of N211. The SFC2-1.93 membrane exhibited good performance (current density of over $1200 \mathrm{~mA} \mathrm{~cm}^{-2}$ at $0.6 \mathrm{~V}$ ) but greater ohmic region loss than Nafion 211, despite the thicker membranes, which increased interfacial resistance between the Nafion electrode and the hydrocarbon membrane. However, SFC2-2.53 exhibited an excellent current density of over 1800 $\mathrm{mA} \mathrm{cm} \mathrm{cm}^{-2}$ at $0.6 \mathrm{~V}$ and performed much better than SFC2-1.93 and Nafion 211 in the ohmic regions, possibly due to the higher proton conductivity of SFC2-2.53 observed ex situ and employment of thinner membranes. The maximum power densities of SFC2-1.93 and SFC2-2.53 are 0.93 and $1.41 \mathrm{~W} \mathrm{~cm}^{-2}$, respectively, under full humidification, promising preliminary results as compared to $1.22 \mathrm{~W} \mathrm{~cm}^{-2}$ for the Nafion 211 reference MEA with fully compatible electrodes and highly optimized catalyst and ionomer loadings, hydration state, and gas diffusion layers. The high cell performance of the SFC2-2.53 membrane is possibly due to the good dimensional stability. It is important that the in-plane swelling is restricted to prevent the delamination of the catalyst layer occurring from a dimensional mismatch between the electrode and membranes.

\section{Conclusion}

In summary, we introduced a series of novel sulfonated poly(arylene ether)s containing a tetra-trifluoromethyl-substituted multi-phenyl structure. The polymers were prepared via polycondensation, and post-sulfonation was processed by chlorosulfonic acid. All the membranes showed high thermal stability, good dimensional stability, excellent oxidative stability, and suitable hydrophilic/hydrophobic microphase separation. Among the membranes, SFC2-2.53 exhibited high proton conductivity of $0.24 \mathrm{~S} \mathrm{~cm}^{-1}$ under fully hydrated conditions. Furthermore, the fuel cell test of the SFC2-2.53 membrane demonstrated an excellent performance with the current density of over $1800 \mathrm{~mA} \mathrm{~cm}^{-2}$ at $0.6 \mathrm{~V}$ and the maximum power density reached $1.41 \mathrm{~W} \mathrm{~cm}^{-2}$ at $80{ }^{\circ} \mathrm{C}$ under fully hydrated conditions, which were superior than those of Nafion 211. The combination of high thermal stability, acceptable dimensional stability, high proton conductivity, and excellent single cell performance makes SFC2-2.53 attractive as a PEM material for fuel cells applications.

\section{Acknowledgements}

The authors are grateful to the Ministry of Science and Technology, Taiwan (MOST 105-2221-E-110-090-) for the financial support of this work. We also gratefully acknowledge Y. Y. Chuang at the Fuel Cell Center of the Yuan Ze University for the TEM measurements.

\section{References}

1 B. C. H. Steele and A. Heinzel, Nature, 2001, 414, 345-352.

2 H. Zhang and P. K. Shen, Chem. Soc. Rev., 2012, 41, 23822394.

3 A. Kraytsberg and Y. Ein-Eli, Energy Fuels, 2014, 28, 73037330.

4 H. Zhang and P. K. Shen, Chem. Rev., 2012, 112, 2780-2832.

5 K. Miyatake, D. Hirayama, B. Bae and M. Watanabe, Polym. Chem., 2012, 3, 2517.

6 J. Rozière and D. J. Jones, Annu. Rev. Mater. Res., 2003, 33, 503-555.

7 H. Jang, S. Sutradhar, J. Yoo, J. Ha, J. Pyo, C. Lee, T. Ryu and W. Kim, Energies, 2016, 9, 115.

8 O. Danyliv, C. Iojoiu, S. Lyonnard, N. Sergent, E. Planes and J.-Y. Sanchez, Macromolecules, 2016, 49, 4164-4177.

9 B. Wang, L. Hong, Y. Li, L. Zhao, Y. Wei, C. Zhao and H. Na, ACS Appl. Mater. Interfaces, 2016, 8, 24079-24088.

10 Y. Zhang, J. Li, L. Ma, W. Cai and H. Cheng, Energy Technol., 2015, 3, 675-691.

11 D. W. Shin, S. Y. Lee, N. R. Kang, K. H. Lee, M. D. Guiver and Y. M. Lee, Macromolecules, 2013, 46, 3452-3460.

12 M. A. Hickner, H. Ghassemi, Y. S. Kim, B. R. Einsla and J. E. McGrath, Chem. Rev., 2004, 104, 4587.

13 B. Liu, G. P. Robertson, D.-S. Kim, M. D. Guiver, W. Hu and Z. Jiang, Macromolecules, 2007, 40, 1934-1944.

14 Y. Chang, G. F. Brunello, J. Fuller, M. Hawley, Y. S. Kim, M. Disabb-Miller, M. A. Hickner, S. S. Jang and C. Bae, Macromolecules, 2011, 44, 8458-8469.

15 Y. C. Huang, R. H. Tai, H. F. Lee, P. H. Wang, R. Gopal, C. C. Lee, M. Y. Chang and W. Y. Huang, Int. J. Polym. Sci., 2016, 2016, 1-8.

16 H. F. Lee, P. H. Wang, Y. C. Huang, W. H. Su, R. Gopal, C. C. Lee, S. Holdcroft and W. Y. Huang, J. Polym. Sci., Part A: Polym. Chem., 2014, 52, 2579-2587.

17 H. F. Lee, Y. C. Huang, P. H. Wang, C. C. Lee, Y. S. Hung, R. Gopal, S. Holdcroft and W. Y. Huang, Mater. Today Commun., 2015, 3, 114-121. 
18 T. J. Skalski, B. Britton, T. J. Peckham and S. Holdcroft, J. Am. Chem. Soc., 2015, 137, 12223-12226.

19 Y. D. Lim, D. W. Seo, S. H. Lee, M. A. Hossain, K. Kang, H. Ju and W. G. Kim, Int. J. Hydrogen Energy, 2013, 38, 631-639.

20 H. Wei, R. Chen and G. Li, Int. J. Hydrogen Energy, 2015, 40, 14392-14397.

21 S. Saha, R. Mukherjee, A. Singh and S. Banerjee, Polym. Eng. Sci., 2017, 57, 312-323.

22 D. S. Kim, G. P. Robertson, Y. S. Kim and M. D. Guiver, Macromolecules, 2009, 42, 957-963.

23 H. C. Lee, H. S. Hong, Y.-M. Kim, S. H. Choi, M. Z. Hong, H. S. Lee and K. Kim, Electrochim. Acta, 2004, 49, 2315-2323.

24 W. Y. Huang and S. Y. Huang, Macromolecules, 2010, 43, 10355-10365.

25 D. J. Jones, B. Purushothaman, S. Ji, A. B. Holmes and W. W. Wong, Chem. Commun., 2012, 48, 8066-8068.

26 S. Banerjee, G. Maier, A. Salunke and M. Madhra, J. Appl. Polym. Sci., 2001, 82, 3149-3156.

27 A. K. Mohanty, E. A. Mistri, S. Banerjee, H. Komber and B. Voit, Ind. Eng. Chem. Res., 2013, 52, 2772-2783.

28 B.-K. Chen, J.-M. Wong, T.-Y. Wu, L.-C. Chen and I. C. Shih, Polymers, 2014, 6, 2720-2736.

29 X. Wang, H. Zhang and S. C. Jana, J. Mater. Chem. A, 2013, 1, 13989.

30 R. Mukherjee, S. Banerjee, H. Komber and B. Voit, J. Membr. Sci., 2016, 510, 497-509.
31 A. K. Mohanty, E. A. Mistri, A. Ghosh and S. Banerjee, J. Membr. Sci., 2012, 409-410, 145-155.

32 L. Chen, S. Zhang, Y. Jiang and X. Jian, $R S C A d v$., 2016, 6, 75328-75335.

33 S. Lee, J. Ann, H. Lee, J.-H. Kim, C.-S. Kim, T.-H. Yang and B. Bae, J. Mater. Chem. A, 2015, 3, 1833-1836.

34 Y. Gao, G. P. Robertson, D.-S. Kim, M. D. Guiver, S. D. Mikhailenko, X. Li and S. Kaliaguine, Macromolecules, 2007, 40, 1512-1520.

35 J. H. Liao, Q. F. Li, H. C. Rudbeck, J. O. Jensen, A. Chromik, N. J. Bjerrum, J. Kerres and W. Xing, Fuel Cells, 2011, 11, 745755.

36 A. Singh, S. Banerjee, H. Komber and B. Voit, RSC Adv., 2016, 6, 13478-13489.

37 S. G. Jo, T.-H. Kim, S. J. Yoon, S.-G. Oh, M. S. Cha, H. Y. Shin, J. M. Ahn, J. Y. Lee and Y. T. Hong, J. Membr. Sci., 2016, 510, 326-337.

38 R. Mukherjee, A. K. Mohanty, S. Banerjee, H. Komber and B. Voit, J. Membr. Sci., 2013, 435, 145-154.

39 J. Peron, A. Mani, X. Zhao, D. Edwards, M. Adachi, T. Soboleva, Z. Shi, Z. Xie, T. Navessin and S. Holdcroft, J. Membr. Sci., 2010, 356, 44-51.

40 C. Fang, X. N. Toh, Q. Yao, D. Julius, L. Hong and J. Y. Lee, J. Power Sources, 2013, 226, 289-298. 